\title{
Numerical simulation of urban berthing quays in a dense housing
}

\author{
Vladimir Korovkin \\ St. Petersburg State Polytechnical University, 195251, St. Petersburg, Russian Federation
}

\begin{abstract}
Calculation of pile quay gantry type as a frame with rigid crossbarand a rigid beam, is a special case of the decision method, presented by $\mathbf{N}$. Gersevanov. This method was widely used in the technical literature and regulatory documents. Translation of manual calculation on the computer almost retained the existing design scheme.

Practical implementation of the engineering universal method offered early to calculation of mooring embankments in relation to a thin wall, is given by anchored inclined piles. In the calculation scheme bottom sealing is not used, and entered stiffness characteristics of the soil, clarifying the nature of the work structure.

The obtained simplified solution determines the lateral pressure in the silo variable width. Engineering calculations showed that pressure is redistributed on the sheet pilling wall and the inclined piles from external soil pressure.

Comparative calculations, taking into account the deformation characteristics of the soil showed a significant impact on efforts in the elements of the embankment compared to method N. Gersevanov.
\end{abstract}

Keywords: coefficients of subgrade resistance, lateral earth pressure, pressure in the conventional silo.

\section{INTRODUCTION}

The practical interest is the reconstruction of the existing urban waterfronts in St. Petersburg. Embankment in the form a gantry bolwerk (of a thin retaining wall with inclined anchor piles) is effective in condition of dense construction, since the construction does not require large amounts of earthwork.

Clarification of the calculation municipal mooring quays gantry type represents an actual task. Because departmental documentation on this quay does not account for the deformation characteristics of the soil.

\section{THE AIM OF THE WORK}

In the current technical literature [1-3] and regulations $[4,5]$ each type of port hydraulic structure can be calculated in different ways. Transfer of manual calculation on the computers significantly reduced the complexity of computing work, but not completely used great opportunities for automation. In view of the most part of methods of calculation are based on provisions and assumptions, which were laid in the era of the lack of computers.

Calculation of mooring designs in software systems, using model of the continuous environment allowed to receive fuller picture of work of a construction in soil. However, the calculation of these structures in programs that use the model of a continuous medium, designed for structural materials, is not strict, as it gives an approximate picture of the behavior of pile foundations in discrete soil environments. Thus additional check of results of calculation, owing to the wide range of an interval of values of basic data, and also in cases of acceptance of rigid seal of a bottom of piles in soil [6-8] is required.

To simplify the understanding of the mechanism of interaction of structural elements with the ground in 2002 was offered a versatile engineering calculation method that can be applied to any design mooring quay [9] and with utilization in the work [10,11].

The purpose of the proposed work is the practical implementation of engineering universal method for computation of berthing type thin wall anchored inclined anchor piles. This is estimated adopted by the calculation scheme and the impact of the assumptions used in departmental norms and values effort in the construction.

\section{REVIEV OF THE LITERATURE}

A significant amount of works of both the Russian, and foreign scientists is devoted to development of rational ways of static calculation of pile embankments of grillage type. For the first time N. Gersevanov gave the common decision of a problem of calculation of pile embankments with a rigid grillage, considering them as a frame with absolutely rigid crossbar on elastic support piles with rigid lower seal (1913). Having equated for unknown movements

ISSN 1691-5402 
of the lower side of a grillage (vertical, horizontal and its turn) N. Gersevanov received three initial equations of a method of deformations. Their decision allowed to pass from movements of a grillage to efforts in piles. These equations are usual conditions of the equation of balance of a rigid body.

Except an analytical way of the calculation developed by N. Gersevanov, the russian scientists B. Lozovsky, F. Dimentberg, V. Hristoforov proposed solutions of the same task by graphic methods. The works of the last years connected with calculation of pile grillages, as a rule, use the classical settlement scheme $[12,13]$.

We will note works of the foreign scientists, who devoted to calculation of pile embankments of grillage type [14 - 17].

Thin retaining wall, sloping piles anchored in respect of the settlement is a frame system with rigid and flexible bolt racks, representing a particular case of the solution proposed by N. Gersevanov [18].

The review of a current state of a problem shows that in technical literature and in normative documents for calculation of pile constructions of grillage type in frames with rigid fixing of the ends of the pile basis N. Gersevanov's decision is used. Thus purpose of depth of rigid seal of piles any or with use of a method of the elastic line doesn't answer the valid work of a construction. Estimating originality of a method of calculation of constructions of the rostverky type offered by N. Gersevanov, we will note that the deformation-free with respect to the interaction of pile foundation in the ground distorts the calculation scheme structures. It brings a certain error when determining efforts in design elements.

\section{TASK SOLUTION}

With regard to the retaining wall, sloping piles anchored consider a system of two beams with different strontium based and interconnected as a condition of joint deformation of structural elements and design of the whole.

The rigel - rigid beam, which is based on the elastic settling focused support, which is loaded as external loads and internal forces from the effects of pile foundation.

The pile basis - system of two beams racks of different rigidity which are rigidly fixed in a seal place in a crossbar, and in the lower part interacting with diverse soil of the basis. The pile basis perceives both external loadings, and the efforts from a crossbar influencing them.

In the settlement scheme the rack-mount frame with various rigidity of a crossbar and racks which can have various inclination is used. Thus unlike a classical method of the calculation used the rigid seal of a bottom of piles appointed randomly at a depth of 1-3 m or method of the elastic line, possibility of their elastic seal is connected with deformation characteristics of soil. Favorable impact of soil of inter pile space on work of an inclined pile which is ignored in a standard method of calculation is in addition considered.

Realization of the offered calculation was carried out in the program SCAD complex.

Initial loadings to calculation of a construction are given in fig. 3a. Lateral pressure upon the top elements of a gantry bulwark includes pressure on cap with a superstructure, a pile row and the sheet pilling.

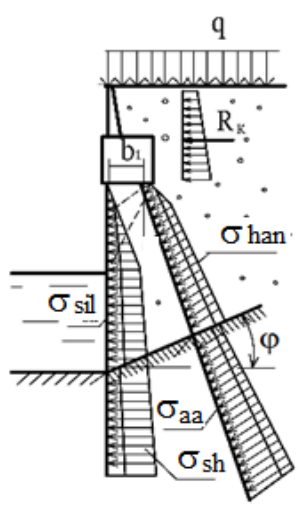

a)

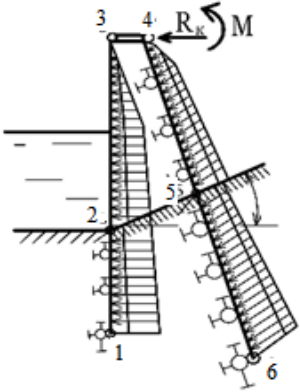

b)
Fig. 1. a) Total plot of pressure of soil. b) Settlement scheme of a construction.

Soil pressure upon an inclined pile number (zone II) represents the sum of the lateral pressure upon the inclined screened plane designated $\sigma_{\mathrm{aa}}$ and pressure from loading of the soil hanging on piles $\sigma_{\text {han }}$ (fig. 1a). Due to the small size of horizontal pressure from the hanging soil upon a rectangular pile, its influence we will consider in $K_{3}$ coefficient at determination of active pressure $\sigma_{\mathrm{aa}}$ on the inclined shielding plane of a pile row (Eq. 1).

$$
\sigma_{\mathrm{aa}}=K_{3}\left(q+\sum \gamma_{i} h_{i}\right) \lambda_{\text {aa }}
$$

where $K_{3}=1.1-1.15$ - the coefficient accounting of the hanging soil on a pile; $q$ - the distributed payload; $\gamma_{i}$ - the specific weight of soil; $h_{i}$ - height of the considered point; $\lambda_{\mathrm{aa}}-$ coefficient of lateral pressure the shielding plane of an inclined pile row, $\alpha=18^{0}$ $25^{\text {II }}$.

Soil pressure upon a sheet pilling wall (zone I) consists of soil pressure in this zone (a silo of variable width), $\sigma_{\mathrm{sh}}$ and the additional resultant pressure of a pile row $\sigma_{\mathrm{r}}$ taking into account the distributing ability of piles. Total plot of pressure of soil and settlement scheme of a construction are represented in Fig. 1.

Lateral pressure in a silo of variable width. Lateral pressure in a point 2 (Eq. 2), a certain straight line at an angle $45^{\circ}-0.5 \varphi$ to a vertical from the beginning of the shielding plane of piles, is equal (Fig. 2a): 


$$
\sigma_{2 \text { sil }}=\gamma_{1} h \lambda_{\mathrm{a}}
$$

Lateral pressure in a silo of variable width in points 3 (Eq.3) and 4 (Eq.4) is defined by the following reception (fig. 2), engineering in margin of safety. We assume that active pressure in a point 3 is defined by pressure of an incomplete prism of a collapse 131110 , and pressure in a point 4 respectively - a prism 1458 . Taking into account this circumstance lateral pressure 3 and 4 is equal in points (fig. 2, a).

$$
\begin{gathered}
\sigma_{3 \text { sil }}=\gamma_{2} h_{1} \lambda_{\mathrm{a} 1} \\
\sigma_{4 \text { sil }}=\gamma_{2} h_{2} \lambda_{\mathrm{a} 2}
\end{gathered}
$$

In margin of safety on we consider basis soil coupling. In case it appears that $\sigma_{3}$ forces $<\sigma_{2}$ forces, value $\sigma_{3}$ forces is defined by the straight line passing through values $\sigma_{3}$ forces and $\sigma_{4}$ forces.

Lateral pressure upon the sheet pilling $\sigma_{\text {ton }}$ represents the sum from conditional silage pressure $\sigma_{\text {sil }}$ at forces in a zone I and additional pressure from the shielding pile row $\sigma_{\mathrm{sh}}$ (Eq. 5). The last is equal to a difference of external pressure $\sigma_{\mathrm{aa}}$ from a zone II and the return silage pressure upon the shielding inclined plane of soil $\sigma_{1}$ forces in a zone 1 taking into account coefficient of distribution of $K_{\mathrm{r}}$ (fig. 2, a).

At determination of additional pressure upon the sheet pilling $\sigma_{\text {sil }}$ from the shielding pile row in departmental norms [18] the offer was used similar N. Smorodinsky's ideas (1937) about distribution of pressure upon the sheet pilling and a pile is proportional to their rigidity. Noted offer, progressive at the beginning of origin of calculations of pile designs, doesn't consider influence of distance of a pile row from a sheet pilling wall, and also cross section of piles and a step of a pile row along the line of a cordon. These factors have more essential impact on a sheet pilling wall and piles than the relation of their rigidity. The simplified decision on definition $\sigma_{\mathrm{sh}}$ by means of coefficient of distribution of $K_{\mathrm{r}}$ is

and many others

$$
\sigma_{\text {ton }}=\sigma_{\text {sil }}+\sigma_{\text {sh }}
$$

Pressure upon the sheet pilling from a zone 2 is taking into account influence of a step of piles through $K_{\mathrm{r}}$ (fig. 2).

$$
\begin{aligned}
& \sigma_{\mathrm{sh}}=K_{\mathrm{r}}\left(\sigma_{\mathrm{aa}}-\sigma^{1}{ }_{\mathrm{sil}}\right) \\
& K_{\mathrm{r}}=(b / n)\left(2 l_{1} / l\right)
\end{aligned}
$$

where $n$ - a step of piles; $l_{i}=c_{i} \operatorname{tg} \varphi$ - variable zone of partial distribution of resultant load behind piles of a sheet pilling wall $\left(\mathrm{c}_{\mathrm{i}}\right.$ - variable distance from a pile to the sheet pilling); $l=b+2 c_{i} \operatorname{tg} \varphi-$ a variable zone of distribution of resultant load between site $b$ piles of a sheet pilling wall; $d$-diameter of the shielding pile.

Deformation characteristics of soil. In practice of port design Fussa-Vinkler's model using the deformation characteristic of soil in the form of coefficients of subgrade resistance was spread at calculation of thin quays. The specified model repeatedly was exposed critics for not the account in it to distributive ability of soil. However, check of model of the continuous environment used in program complexes with data of natural researches showed that influence of distributive ability in relation to soil having discrete structure is overestimated.

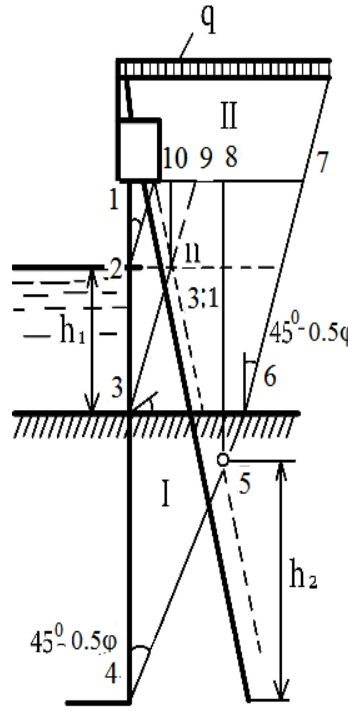

a)

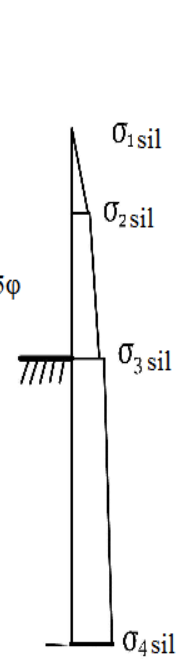

b)

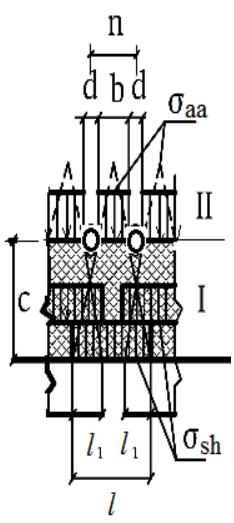

c)
Figure 2. Settlement schemes to determination of lateral pressure in a zone I. a) The simplified scheme. b) The specified scheme defining intensity from a condition of the maximum plane of a collapse. c) Determination of pressure of a pile row upon the sheet pilling.

The solution of the differential equation of a bend of the beams leaning on the continuous (vinklerovsky) elastic basis on a method of local deformations, doesn't represent special difficulties, but contains four constant integration, which need to be defined from entry conditions.

First-hand experiences show that the coefficient of subgrade resistance for natural soil isn't a constant, and depends as on the size of specific pressure upon soil, and on the area of transfer of loading that it is necessary to consider at calculations.

The generalized methods of definition of deformations of soil consider both the general elastic, and local inelastic deformations of soil. From these methods we will note P. Pasternak's - V. Vlasov's method - the two-parameter elastic basis according to which the soil basis is characterized by coefficients of a subgrade resistance of compression and local elastic shift. The method of the structural restored by I. Cherkasov's - G. Klein's deformations, considering the general restored deformations (elastic and the adsorptive) and residual (structural). In the last method the restored deformations are accepted for 
linearly deformable and are characterized by the coefficient similar to coefficient of an elastic halfspace.

The theory of calculation of the designs lying on the deformable basis with one and two coefficients of a subgrade resistance gained development in works, made by: A. Dinnik, P. Pasternak, M. Gersevanov, N. Zhukovsky, A. Krylov, A. Umansky, G. Dutov, V. Kiselyov, S. Golushkevich, B. Korolyov, N. Snitko, V. Vlasov, N. Leontyev Among foreign scientists were engaged in this task: H. Westergaard, H. Bufler, H., Lieb, G. Meier [20], Y. Cheung, O. Zienkiewicz [21], C. Desai, J. Christian [22], A. Ioannides etc.

Due to changes in the coefficient of a subgrade resistance on depth (for piles) and plan (for slabs) used the so-called coefficient of soil stiffness. With regard to the calculation of different types of mooring facilities are invited to use the stiffness coefficient of the base connecting the stiffness coefficient of soil elastic and limit states for the entire load cycle [23]. For practical use, it is piecewise linear values in each section of the structural element of the five intervals of the entire load.

Below is a comparison of the two calculations on the example of the type of quay gantry, built on the shores of the Neva River in St. Peterbrge [24].

Example. Basic data. Load on the surface of the filling $\mathrm{q}=40 \mathrm{kN} / \mathrm{sq} . \mathrm{m}$. Free height of wall $\mathrm{N}=7 \mathrm{~m}$, thickness of the sheet pilling is $30 \mathrm{~cm}$, the section of anchor piles is $40 \times 40 \mathrm{~cm}$, a pile step $\mathrm{n}=1.0 \mathrm{~m}$, a bias of piles $3: 1\left(\mathrm{a}=18^{\circ} 25^{\prime}\right), \mathrm{h}_{\mathrm{k}}=2.2 \mathrm{~m}$, settlement width of $\mathrm{a}$ crossbar of $\mathrm{b}=1.5 \mathrm{~m}$.

TABLE 1

THE CALCULATION RESULTS PROMENADE TWO METHODS

\begin{tabular}{|l|c|c|}
\hline \multicolumn{1}{|c|}{ Name } & $\begin{array}{c}\text { Classical } \\
\text { method } \\
{[18]}\end{array}$ & $\begin{array}{c}\text { Universal } \\
\text { method }^{1} \\
{[9]}\end{array}$ \\
\hline $\begin{array}{l}\text { Moment at the top sealing of } \\
\text { the sheet pilling [kNm] }\end{array}$ & -0.0 & -142.0 \\
\hline $\begin{array}{l}\text { Moment at the top sealing of } \\
\text { the pile [kNm] }\end{array}$ & -38 & 48 \\
\hline $\begin{array}{l}\text { Moment in the span of the } \\
\text { sheet pilling [kNm] }\end{array}$ & 95 & 77 \\
\hline $\begin{array}{l}\text { Moment in the span of the } \\
\text { pile [kNm] }\end{array}$ & -92.5 & -138.8 \\
\hline $\begin{array}{l}\text { Moment at the bottom } \\
\text { sealing of the sheet pilling } \\
\text { [kNm] }\end{array}$ & -71 & -77 \\
\hline $\begin{array}{l}\text { Moment at the bottom } \\
\text { sealing of the pile [kNm] }\end{array}$ & -377 & -273.0 \\
\hline $\begin{array}{l}\text { The longitudinal force in the } \\
\text { vertical pile [kN] }\end{array}$ & 581 & 503 \\
\hline $\begin{array}{l}\text { The longitudinal force in the } \\
\text { inclined pil [kN] }\end{array}$ & 5.6 & 10.97 \\
\hline $\begin{array}{l}\text { Horizontal displacement of } \\
\text { the top [mm] }\end{array}$ & & - \\
\hline
\end{tabular}

Settlement characteristics of soil of the basis: $\gamma_{\mathrm{we}}=$ $10 \mathrm{kN} / \mathrm{m}^{3}, \varphi=20^{\circ}, \mathrm{s}=0.015 \mathrm{MPa}$; backfill soil: $\gamma=$ $18 \mathrm{kN} / \mathrm{m}^{3}, \gamma_{\mathrm{we}}=10 \mathrm{kN} / \mathrm{m}^{3}, \varphi=30^{\circ}$. Module of elasticity of material of a design of $\mathrm{E}_{\mathrm{Sh}}=\mathrm{E}_{\mathrm{s}}=2.1 \cdot 10^{4}$ $\mathrm{MPa}$. Rigidity of the sheet pilling and piles on $1 \mathrm{~m}$ wall lengths: $\mathrm{E}_{\mathrm{Sh}} \mathrm{I}_{\mathrm{Sh}}=4.7 \cdot 10^{8} \mathrm{KN} \cdot \mathrm{cm}^{2} ; \mathrm{E}_{\mathrm{S}} \mathrm{I}_{\mathrm{S}}=2.98$ $10^{8} \mathrm{kN} \mathrm{sm}^{2}$. Deformation characteristics for soil of a backfill and the basis in the form of horizontal and vertical coefficients of a subgrade resistance of soil of a backfill and basis for the sheet pilling and piles were accepted with use of normative documents [5]. The calculation results are shown in Tab. 1.

1. The calculation on the universal method was performed by student K. Kokoreva.

\section{ANALYSIS OF THE CALCULATION RESULTS}

The comparison of calculation results by the two methods showed their incommensurability of individual values of the forces in the elements of the structure. This has arisen because of the different calculation schemes in the considered methods. So, based on [18] efforts are rigidly fixed to the frame arise from the active earth pressure on them and from turn the whole structure relative to the lower seal. In the calculation [9] hard sealing the bottom rack is not used, and the rotation of the whole structure starts to prevent the reactive pressure of the soil in disconnected space on the inclined pile. However, depending on the stiffness of the soil plot of bending moments in the pile can change the direction. Universal method that allows the variation of the values of the horizontal and vertical coefficients of subgrade resistance (without considering them in the filling) upwards to get more or less comparable amount of effort with departmental standards. However, in this case, the actual stiffness characteristics of the foundation soil will be distorted.

\section{CONCLUSIONS}

1. In the existing technical literature and normative documents each type of the port hydraulic engineering construction has the method of calculation. Calculation of the pile embankment of gantry type in the form of a frame with absolutely rigid crossbar on elastic support piles with rigid lower seal, represents a special case of the decision (deformation-free in soil) Gersevanov's method. Transfer of manual calculation on the computer significantly reduced labor input of computing works, nevertheless the part of methods of calculation is based on provisions and assumptions which were put in the absence of the computer.

2. Practical realization of the engineering universal method offered early to calculation of mooring embankments in relation to a thin wall, anchored by inclined anchor piles is given. The calculation used the stiffness characteristics of the cross-beams, piles and soil, the latter are absent in the classical method. 
3. The simplified solution of determination of lateral pressure in a silo of variable width is received.

4. Engineering reception of calculation of additional pressure upon a sheet pilling wall from pressure upon an inclined pile row is shown.

5. Comparative calculations promenade with various values of the stiffness characteristics of the soil interacting with the pile elements, showed their significant impacts on the classic design scheme of the building. In the case of flexible racks and dense sub-soil (without taking into account the stiffness of the soil) backfill settlement efforts more or less comparable with the method N. M. Gersevanov, which can be considered as a special case of the universal method. In other cases, efforts in the elements of the embankment on the universal method change up or down in comparison with the classical method of calculation.

6. During the construction of the gantry bulwark of rectangular reinforced concrete piles, it is recommended to limit its free height of up to seven meters, due to the emergence of a large bending moments and the longitudinal force in the inclined pile.

\section{REFERENCES}

[1] G.N. Smirnov, V.V. Aristarkhov, S.N. Levichev, A.G. Sidorov, E.A. Korchaginю. Ports and port facilities. Ed. DIA, Moscow, 2003, 463 p.

[2] P.I. Yakovlev, A.P Tyurin, Y.A. Portucel. Port hydraulic structures. Ed. Transport, Moscow, 1990, 320 p.

[3] P.P. Kulmach, V.P. Filippenok, N.G. Zaritovskiy. Marine hydraulic structures. Ch. II, Mooring, offshore and shore protection structures. LVVISU, Leningrad, 1991, $391 \mathrm{p}$.

[4] Design of the mooring quays, CH-RF 54.1-85, MRF RSFSR, Moscow, 1991, $247 \mathrm{p}$.

[5] Instruction on designing marine berthing and shore protection structures. RD 31.31.55.93 RD 31.31.55.93, MMF, Moscow, 1996.

[6] PLAXIS. Plaxis v. 8.2, Finite Element Code for soil and rock analyses. Netherlands, 2002.

[7] Program GEO5 for design and analysis of retaining armagrandi and gravitational structures Certificate of conformity No ROSS CZ.SP.N, Moscow, 2012.
[8] Program Cluster, version 1, Engineering and consulting centre for Foundation. Moscow. to the hydraulic port facilities. Advanced Materials Research, Vols. 945-949, 2005, pp. 541548.

[9] V.S. Korovkin. Universal method of calculating berthing quays The first scientific-practical conference Sea and river ports of Russia, Moscow, 2002, 103-105 pp.

[10] T. Dang, V. Korovkin. Engineering kinematic theory of ground contact pressure in the annex to the hydraulic port facilities. Advanced Materials Research, Vols. 945-949, 2014 pp. 541-548.

[11] A. Melentev, V. Korovkin. Calculation of Retaining Walls with Anchoring at Different Levels Applied Mechanics and Materials, 725-726, 2015, pp. 185-189.

[12] V.V. Znamensky. Engineering calculation method for horizontally loaded group of piles. Ed. DIA, Moscow, 2000, $128 \mathrm{p}$.

[13] A.Y. Budin. City and harbour quays Ed. Polytechnic, St. Petersburg, 2014, $418 p$.

[14] CUR-publication 166. Damwand constructies | ISBN 90376 0638 | CUR, Gouda, the Netherlands, 4th issue, 2005.

[15] Grabe J. Sheet Piling Handbook Design. Thyssen Krupp GfT, Bautechnik GmbH HSP HOESCH. Spundwand and Profil GmbH, Hamburg, 2008.

[16] Design Manua. 1. Steel Sheet Piling United States, Steel Updated and reprinted by U. S. Department of Transportation. FHWA with permission, 1984.

[17] A Handbook of Quay Walls. CUR Centre for Civil Engineering Research, Havenbedrijf Rotterdam NV, Gemeentewerken Rotterdam. Published by Taylor \& Francis, the Netherlands ISBN: 978-0-415-36439-3, 2005.

[18] Guidelines for the design of the mooring quays, Part VI, Embankment reinforced concrete pile with inclined ankerwyke piles, AK 2070, Lengiprorechtrans, Leningrad, 1970, 32 p.

[19] V.S. Korovkin. Calculation exploited berthing facilities with regard to reologicheskih properties of the base and the harsh climatic conditions of the continental shelf. Sankt-Peterburg, 2013, 88 p.

[20] H. Bufler, H. Lieb, G. Meier. Frictionless contact between an elastic stamp and elastic foundation, Ing. Arch. Bd. 52, No.1/2, 1982.

[21] Y.K. Cheung, Zienkiewicz O.C. Plate and tank on elastic foundation. An application of finite element method. Intern. J, Solid struct, vol. 1, No. 4, 1965.

[22] C.S. Desai, J.T. Christian. Numerical methods in geotechnical engineering Mc Graw-Hill Inc, 1977.

[23] V.S. Korovkin. Engineering kinematic theory the contact pressure of the soil in the application to the calculation of certain types of foundations. Magazine of civil Engineering, No. 6, 2013.

[24] V.S. Korovkin. Load-bearing capacity of pile foundations berthing quays St. Petersburg river port Collection of papers, dedicated to the 300th anniversary of St. Petersburg. St. Petersburg, 2003, $170-175$ pp. 